\title{
The Future of Higher Education: A New Paradigm Shift Addressing Students' Diversity
}

\author{
Khalid Arar and David Chen
}

\section{Introduction}

Recent higher education (HE) trends, including broader accessibility, privatization, increased demands for accountability, and technological implementation, have largely neglected consideration of human diversity, including the individual learner's nature and learning style. Two distinctive scientific perspectives pertain to these individual differences. In addition to the classical perspective of a bell-shaped normal distribution of mental abilities, a new perspective driven by behavioural genetics, neuroscience, learning science, and molecular biology reveals the immense complexity of the mind's architecture and functions in the population. Knowledge technologies might offer an innovative educational response to the immense diversity of students' and the complexity of the learning processes.

Technology should be defined as the human capacity to solve existential problems so that technology is first and foremost a cognitive trait, rather than a tool or machine. Today's educational policies seem to be dominated by an erroneous perception of man, aspiring to achieve uniform standards as if people were machines. We suggest that the biggest problem for present-day HE is the persistent overlooking of individual learner differences while its prevailing conceptualization is based on behaviourist principles. Ignoring human diversity and failing to address this fact is the main cause for educational ineffectiveness and inequality that prevails almost everywhere.

This essay suggests how major technologies might improve equity and efficacy through the recognition and resolution of the problem of individual differences and diversity in future HE institutions, noting the promise of "learning analytics" intended

\footnotetext{
K. Arar $(\varangle)$

Texas State University, San Marcos, USA

e-mail: khalidarr@gmail.com

D. Chen

Tel-Aviv University, Tel Aviv-Yafo, Israel

e-mail: chen@tauex.tau.ac.il 
mainly to introduce adaptive education and artificial intelligence usage in knowledge spaces and provide alternative curriculum choices to meet personal learning needs. Such developments should meet UNESCO's call to rethink and reshape higher education in line with increasing world complexity. The article concludes with several changes in the knowledge world and possible consequences for HE systems to enable them to address students' diversity and produce appropriate adaptive learning.

\section{Current Global Higher Education Policy}

Higher education institutions (HEI's) have undergone unending reforms designed to respond to the priorities of commercial markets and governments and to render universities more economic, efficient, and effective. However, by the 1990s, many national governments believed that the future lay in a 'global knowledge economy'. They implemented policies to repurpose HE to produce knowledge, skills and graduates that would generate intellectual capital and innovative products and make their countries more globally competitive. These reforms relied on neoliberal ideas aimed at turning universities into autonomous and entrepreneurial 'knowledge organizations' by prompting competition, and opening them up to private investors, to maximize individuals' skills in global labour markets (Shore and Wright 2017, p. 1). These policy narratives positioned universities as static entities within a market economy. An alternative narrative would see the university as a dynamic and fluid set of relations within a wider 'ecology' of diverse interests and organizations (Shore and Wright 2017).

Under pressure to produce 'excellence', foster social cohesion, improve social mobility, and challenge received wisdom (Brooks and Waters 2011), the boundaries of the HEI are being constantly negotiated while their core values and distinctive purpose change towards 'academic capitalism'. The following major trends influence HEIs today:

1 State withdrawal from investments in universities: state funding per student declines and cost-sharing shrinks.

2 New competitive regimes: Funding and assessment regimes are created to increase national and international productivity and competition between universities. Ranking is introduced, including ranking of institutions, disciplines, departments, and even individuals. Funds are then allocated to higher ranking HEIs, creating an 'audit culture'.

3 Administrative Bloat and Academic Decline, an extraordinary growth in the number and statuses of university administrators far beyond the growth in the number of faculty or even students is partially due to harvesting of data by the ranking industry and enormous rise in government regulations. Administrators become those who determine the university's core functions. Many universities have dropped the term 'academic support staff' in favor of terms like 'senior administrators' and 'pro- 
fessional staff', while faculty are managed as 'human capital' and a resource, and universities have become 'business corporations' (Levin and Greenwood 2016).

4 Privatization: faced with diminishing state funding and budget cuts, universities seek alternative funds, entailing fostering lucrative entrepreneurial partnerships with industry, conducting commission research for businesses and government, commercializing the university's intellectual property through patents and licenses, engaging proactively in city development. HEIs compete to recruit additional higher fee-paying international students, effectively generating the 'export of education'. Thus, HEI education has become a private, positional investment rather than a public good, while students' grants are replaced with loans. This has been coupled with a massive hike in student fees or what is called 'cost-sharing' by ministries and world bank experts (McGettigan 2013).

Global motilities, migration and internationalization lead to widening participation, diversity, equity and inclusion necessitating attempts to balance between expansion and quality assurance (Arar et al. 2019; Huisman 2009). In 2019, it was estimated that $3.5 \%$ of the total global population, or 272 million people, were on the move (IOM 2020). In 2016, there were 3.3 million international students (OECD 2017), most (58\%) moving from the east (China, India, Hong Kong, Singapore), mainly to Anglophonic states, including the USA, Australia, UK, Canada and New-Zealand which received $65 \%$ of these students (Arar et al. 2020).

5 Under globalization, a market-driven process, and knowledge-based production have become the distinguishing characteristic of globalized economies (Altbach et al. 2018). Technological developments have transformed the world economy's organization and the way that HE is provided. Thus, globalization of HE has shaped HEIs over three distinct, interrelated phases: (1) a surge in cross-border student flow, (2) the development of education hubs and branch campuses, and (3) most recently - program mobility, revolutionized by mass courses such as Massive Open Online Courses (MOOCs), enable more distance learning while shining new campuses espouse lifelong access to 24/7 education for all.

The knowledge society has altered the relationship between the public and individual knowledge stock. Theoretically, learning can take place without mediating agencies. Do these trends spell the end of the public university? Perhaps not, because autonomous or independent learning requires strong motivation, self-discipline and the ability for formal thinking; only a very small percentage of the population have these capabilities.

Actually, access to universities has increased massively, and technological innovations, including online learning provide responses to the challenges of privatization and marketization. Indeed, despite reduced public investment, citizens' expectations from the HEIs are even higher than in the past, believing that HEIs should educate students to be exemplary citizens for tomorrow's world, a world where they will need more sophisticated skills, responding to the interaction between research and socio-economic development, and providing continuous innovation and knowledge transfer to external stakeholders. 'Doing more with less' is now an imperative that 
characterizes the funding of HEIs' operations and institutions (De Witte and LópezTorres 2017).

\section{The Future of Higher Education}

Traditionally, HEIs partition knowledge into different disciplinary faculties: science, liberal arts, medicine, engineering etc. Teaching and learning follow a linear structure through three stages: undergraduate, graduate and Ph.D. Socially, HEIs are highly selective institutions allowing access by an average thirty percent of the population (Drucker 1993; Whitty and Furlong 2017). Selection begins at the undergraduate level and continues more fiercely to the third level with remarkable difference between the selection rate of Ivy League institutions and community colleges. Yet, the bell shape distribution of mental traits apparent in the PISA database indicates that only three percent of this population become the intellectual elite that establishes society's productive leadership. Thus, different goals should be set for each of the three HE stages in line with students' abilities.

(1) The knowledge society's nature has entirely changed from the Enlightenment focus on local national state, national culture and identity into an extended world perspective implying global problem solving, multiculturalism, English as a lingua franca, social networking, and wide cooperation rather than clash and conflict. The OECD (2018a) offers an international futuristic vision, suggesting an ecosystem approach that would change the static, predetermined curriculum to a flexible, dynamic curriculum to cope with the various socio-economic problems in a complex, uncertain new world. New skills to be developed would include critical thinking, creativity, self-efficacy, and regulation as well as self-regulation and autonomy.

(2) The PISA international comparative study provides perhaps the best big database to inform policies and practices, reflecting the realities of education, since it collects learning data from 79 countries and millions of learners (OECD 2018b). A critical evaluation of PISA 2018 by Schleicher Andreas (2019) provides essential guidance for any future design of a learning system as PISA results establish immense differences between and within countries, opposing the idealistic vision reflected in many policy papers.

\section{What Next: Suggestions for a New Paradigm Shift}

Given this global debate on how knowledge, education and learning need to be reimagined in a complex and uncertain world, it becomes clear that universities can play a crucial active role in shaping the future if they can conceive and implement appropriate institutional transformation. This section identifies future challenges for 


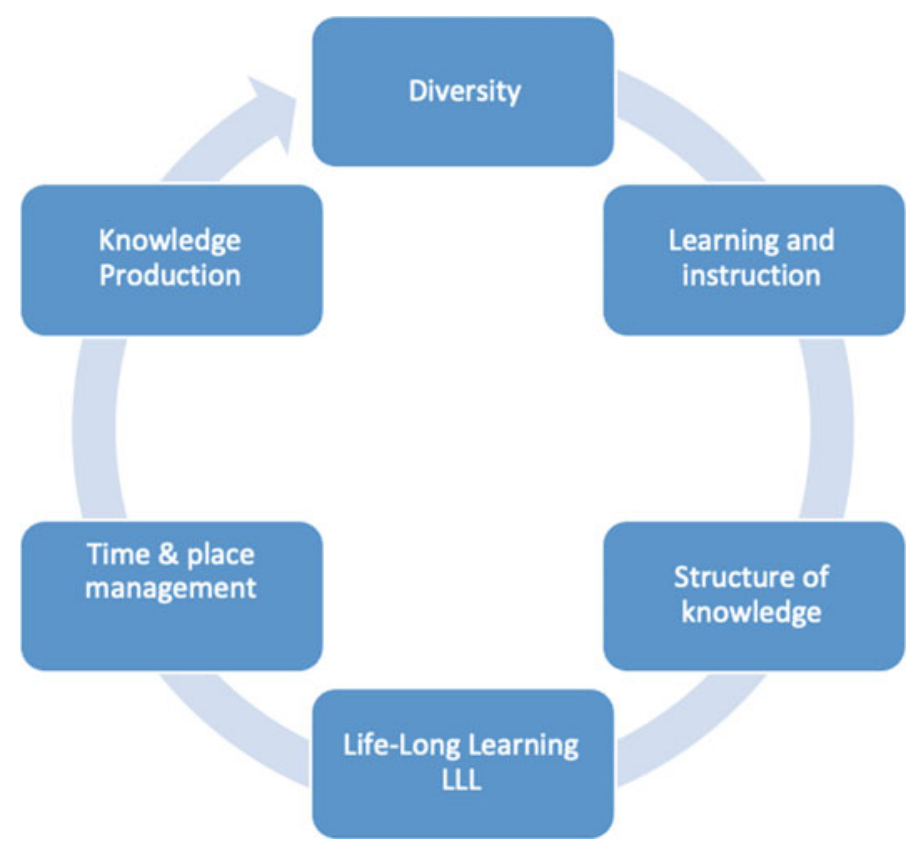

Fig. 1 Coping with diversity and individual differences in learner populations

the HEIs and sets the base for the next suggested paradigm shift, also addressing issues of diversity and inclusion, as presented in Fig. 1.

To retain their relevance to present-day life and to serve rapidly changing needs for the production and application of knowledge, HEIs must adapt to the following changes:

- The most significant aspect of the knowledge era is the exponential growth of knowledge; however, individual memory has remained practically static. An individual cannot make smart choices nor can a professional committee construct a reasonable curriculum without a clear knowledge technology, e.g. AI or Learning Analytics. These technologies are not yet mature enough for educational practice, but they are the only tools that can cope with the current complex quantities of the public knowledge stock.

- Learning and instruction need to consider growing understandings of the learning process and teaching strategies (neuroscience, cognitive psychology and education). It is important to recognize the distinction between declarative (symbolic) knowledge, the dominant knowledge delivered in universities transmitted in lectures and texts, and non-declarative knowledge without words (emotional knowledge, motoric knowledge, visual knowledge), which has been largely overlooked until recently. Stemming largely from learning through experience in tacit knowledge learned through experimentation (e.g. chemistry, engineering, physics). This knowledge is rarely given adequate coverage in educational institutions and should 
be recognized and employed in entrance exams and selection of candidates and over the academic programs. Teaching and learning will require collaborative, creative students who know how to learn well. To identify such applicants, universities will need to fulfil their responsibility to pre-collegiate education. Evaluation methods should correspondingly alter: from the testing of mastery of taught knowledge to assessments, which evaluate whether students are prepared for future learning. Students will be presented with new content they have not been taught in class - and evaluated by how well they assess and learn from that content.

- Diversity: The Personality Profile indicates that students' emotions are intertwined in learning, and universities should apply the concept of "adaptive education while aiming to meet learners' diversity." As science progressively reveals how different people learn and how to produce conditions that optimize learning, HIE pedagogies should be reconsidered to enable adaptation to meet students' diverse needs. New technologies can collect precise data on what is and is not helping students, enabling revision and continuous improvement of instruction and the underpinning scientific theories. Studies can be adapted to individual differences by relaxing choices, personalization of curricula, offering flexible time and place of learning and providing differential graduations. Adaptive education should replace the present rigid mechanical organization of learning. Open access universities that serve up to $30 \%$ of the student population, should adopt more flexible modular organization of knowledge beyond the present B.A, M.A, PhD pathway, creating smaller modules accumulated towards an academic degree, and professional learning during the working span to enable continuous learning.

- The reservoir of public knowledge grows exponentially, but human ability to absorb the knowledge remains static due to the inherent limitation of individual memory capacity. However, knowledge technologies can now extend human capacity to make choices in both chaotically organized and public stock knowledge.

- Pessimistic visions suggest that technology would replace HEIs' faculty, curriculum, and classrooms, because the individual understands how to interact directly with the stock of knowledge, without mediation agencies. This hypothesis does not stand up to the test of reality. Despite the success of the Open Universities, MOOCs and CORSERA, $90 \%$ of the students in the Open University and CORSERA reported that they preferred to learn in an organizational framework, indicating there is still a need for curricula, lecturers and educational institutions.

- Lifelong Learning (LLL), expands the HEIs' target population and the span of knowledge and relates to different age groups of students. While the present age is $18-30$, the future age span is expected to be $16-80$. This would cover both learning for an academic degree, and elective learning, addressing high school and other age groups and include learning in the community, learning for retirees (e.g. cultural and leisure studies), professional development for the industry (at work and in HEIs), second chance learners, special education, social projects (health, ecology, technology), and individual enrichment. College admission will no longer serve as the dreamy endpoint, rather just one chapter in a long life of learning.

- Managing time and place: Students should be able to study at any time and in any location, for example in a pandemic, attempts were made to facilitate dis- 
tance learning. Optimally, management of time and space would provide a hybrid framework, including classrooms, personal mentoring, experimental labs, workshops, independent learning and distant learning. Knowledge modules should be standardized, and there should be a global accreditation system. Such a shift facilitates inclusion of different types of students, e.g. migrants, displaced persons and international students or students in work etc.

- Production of knowledge needs to alter. In addition to the knowledge in HEIs there is now common wisdom, machine learning and business world knowledge. Universities' departmental fiefdoms need to be broken up or rearranged to support interdisciplinary efforts needed to create innovative solutions to major societal problems, and bureaucratic and cultural barriers to problem-focused research must be removed. However, the essential agent that can contribute well-based universal scientific knowledge remains the HEI.

Thus, despite the Knowledge Revolution, the long-awaited change is not a choice of one of two alternatives. Despite the current experience of online academic studies in the shadow of the epidemic or the Open University's attempts to lead international learning through radio, television, or the Internet, there is still an urgent need for oncampus learning, HEIs' research especially in science, agriculture and engineering, and academic mentoring, since most people are unable to learn autonomously and need mediation, and most prefer learning in groups. Universities should move to ecosystem planning, exposing knowledge to the community, delivering services, and sharing platforms for the public good. Seventy years ago, the IAU declared the principles it would promote: "the right to pursue knowledge for its own sake and to follow wherever the search for truth may lead; the tolerance of divergent opinion and freedom from political interference". In the spirit of this declaration, this innovative paradigm shift can be catalysed and led by the IAU, assisting universities to move to an ecosystems approach, exposing contemporary, relevant knowledge to the community, and sharing global platforms for the public good.

\section{References}

Altbach, P.G., Reisberg, L., Salmi, J., \& Froumin, I. (2018). Accelerated universities, ideas and money combine to build academic excellence. Global Perspectives on Higher Education, 40. Leiden; Boston: Brill.

Arar, K., Haj-Yehia, K., Ross, D.B., \& Kondakci, Y. (2019) Higher education challenges for migrants and refugee students in a global world. In K. Arar, K. Haj-Yehia, D.B. Ross \& Y. Kondakci (eds.) Higher education challenges for migrants and refugee students in a global world (pp. 1-23). New York: Peter Lang.

Arar, K., Kondakci, Y., \& Streitwieser, B. (2020). Higher education for forcibly displaced, migrants, refugees and asylum. Higher Education Policy, 33: 195-202.

Brooks, R., \& Waters, J. (2011) 'Student mobility, migration and the internalization of higher education', New York: Palgrave Macmillan.

De Witte, K., \& López-Torres, L. (2017). Efficiency in education: A review of literature and a way forward. Journal of the Operational Research Society, 68: 339-363. 
Drucker, Peter, F. (1993). Post-capitalist society. NY: Harper Collins.

Huisman, J. (2009). International perspectives on the governance of higher education, alternative frameworks for coordination. London: Routledge.

IOM [International Organization for Migration] (2020) 'World migration report 2020', Geneva, Switzerland: IOM.

Levin, L., \& Greenwood, D. J. (2016). Creating a new public university and reviving democracy: Action research in higher education. Oxford: Berghahn.

McGettigan, A. (2013). The university gamble: Money, markets and the future of higher education. London: Pluto.

OECD. (2017) International migration outlook 2017, Paris: OECD.

OECD (2018a). The future of education and skills: Education 2030. Paris: OECD. Retrieved from: https://www.oecd.org/education/2030/E2030\%20Position\%20Paper\%20(05. 04.2018).pdf (26.07.2020).

OECD (2018b). Pisa: Program for International Student Assessment. OECD. Retrieved from: https://www.oecd.org/pisa/ (26.07.2020).

Schleicher Andreas (2019). PISA 2018: Insights and interpretations. France: OECD. Retrieved from: https://www.oecd.org/pisa/PISA\%202018\%20Insights\%20and\%20Interpretations\%20FINAL \%20PDF.pdf(26.07.2020).

Shore, C., \& Wright, S. (2017). Privatizing the public university: Key trends, countertrends and alternatives, In S. Wright \& C. Shore (eds.), Death of the public university: Uncertain futures for higher education in the knowledge economy (pp. 2-27). New York: Berghahn.

Whitty, G., \& Furlong, J. (2017). Knowledge and the study of education- an international exploration. Oxford: Symposium Books.

Khalid Arar is Associate Professor of Educational Leadership and Policy at Texas State University and an Associate Editor of the International Journal of Leadership in Education. He was Dean of Research, at The Centre for Academic Studies and former President of Al-Qasemi Academic College of Education. For the past two decades, his research has focused on both K12 and higher education policies through the lens of equity and diversity.

David Chen is former Dean of the School of Education at Tel-Aviv University and visiting scholar in Harvard, Stanford, MIT and Oxford University. He recently initiated the School of the Future Project at Tel-Aviv University.

Open Access This chapter is licensed under the terms of the Creative Commons Attribution 4.0 International License (http://creativecommons.org/licenses/by/4.0/), which permits use, sharing, adaptation, distribution and reproduction in any medium or format, as long as you give appropriate credit to the original author(s) and the source, provide a link to the Creative Commons license and indicate if changes were made.

The images or other third party material in this chapter are included in the chapter's Creative Commons license, unless indicated otherwise in a credit line to the material. If material is not included in the chapter's Creative Commons license and your intended use is not permitted by statutory regulation or exceeds the permitted use, you will need to obtain permission directly from the copyright holder. 